\title{
Analysis of the Marketing Strategy of WeChat Reading App Based on the Four Ps of Marketing
}

\author{
Yuan Peng ${ }^{1, a}$ \\ ${ }^{1}$ School of Business Administration, Chongqing Technology and Business University, Chongqing 400020, China \\ apcy99411@163.com
}

\begin{abstract}
With the development of Internet technology and mobile terminals' popularity, mobile reading apps have become a common way of reading in today's society. This paper takes the WeChat Reading app as the object of studying. It examines the product, pricing, channel, and promotion strategies of the WeChat Reading app from The Four Ps of Marketing perspective. Through analysis, the combination of reading and social friend chain has become the most significant advantage of WeChat Reading over other mobile reading apps. At the same time, it also faces many problems such as the shift of reading focus, the proliferation of superficial reading, and a relatively single business model.This paper gives corresponding suggestions through analysis that the WeChat Reading app could be configured with more reading resources and improved platform innovation. The study is beneficial to the continuous iterative updating and better development of WeChat Reading and provides implications for other platforms of the same type.
\end{abstract}

Keywords: Mobile reading app, WeChat reading app, The Four Ps of Marketing, Marketing strategy.

\section{INTRODUCTION}

With the advent of the Internet era, people's demand for reading and consumption patterns has changed dramatically in the context of "reading for all. The 17th National Reading Survey released by the China Press and Publication Research Institute shows that the contact rate of mobile reading mode (online reading on the internet, mobile phone reading, e-reader reading, pad reading, etc.) is $79.3 \%$, up 3.1 percentage points from $76.2 \%$ in 2018 , which is higher than the contact rate of paper media. This shows that people are slowly moving from the traditional paper reading mode to the mobile reading mode, and mobile reading has become the primary way of reading. This paper adopts a case study research method and chooses the WeChat Reading app as an example. The main reasons for selecting the WeChat Reading app are that WeChat Reading has created a reading + social reading model. Besides, WeChat Reading, as a rising star in mobile reading, has been launched to rise to the momentum of quickly occupy part of the market, becoming a dark horse in the mobile reading hours. The Four Ps of Marketing theory analyses its marketing strategy's characteristics, analyses its problems and makes suggestions for its future development.

\section{LITERATURE REVIEW}

\subsection{Introduction to The Four Ps of Marketing theory}

American marketing scientist Jerome McCarthy proposed the four Ps of marketing theory in the 1960s. The four Ps of marketing theory's core content is mainly a combination of four basic strategies: Product, Price, Promotion and Place.

\subsection{Mobile reading}

Mobile reading is a kind of reading behaviour based on mobile device applications. Applications are also known as reading apps. It is a new media form, is the new form of traditional publishing to adapt to the development of the mobile Internet, is a form of expression of digital publishing"[1]. Specifically, mobile reading in a broad sense refers to all reading behaviour using mobile terminals, including browsing mobile websites through browsers and reading articles in news clients, newspaper clients, magazine clients, microblogs, and WeChat. In a narrow sense, Mobile reading refers to the behaviour of directed reading through mobile terminals $^{[2]}$. Du Jianhua analyses the current trend of 
mobile reading and countermeasures ${ }^{[3]}$. Li $\mathrm{Wu}$ and Liu $\mathrm{Yu}$ have conducted a comparative study on college students' mobile reading behaviour in China, Japan, and Korea $^{[4]}$. There are fewer articles that study mobile reading apps based on the four Ps of marketing theory. Therefore, this paper uses the four Ps of marketing theory to study the mobile reading-WeChat reading app from four aspects: product, price, place and promotion, and at the same time analyze its problems and propose optimization measures.

\section{CASE STUDY}

\subsection{Introduction of WeChat Reading app}

WeChat Reading was officially launched in August 2015. WeChat Reading is based on the relationship chain of WeChat, with the core concept of "social experience + reading experience". The development history of the WeChat Reading app is shown in Figure 1 .

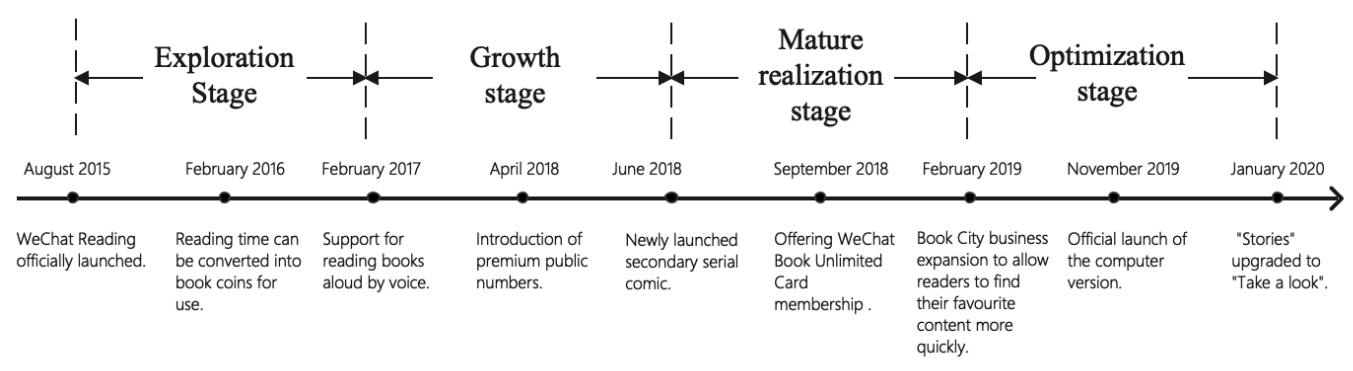

Figure 1 The development of the WeChat Reading app

This paper analyzes the development of WeChat Reading by dividing it into four stages. As can be seen from Figure 1, August 2015 to February 2017 is the first stage. WeChat Reading app is in the exploration stage to clarify the product positioning and improve the essential functions. February 2017 to June 2018 was the second stage of growth, with WeChat Reading gradually enriching its functions and content types. June 2018 to February 2019 is the third stage of mature realization, mainly exploring paid reading services, launching "unlimited card membership", which allows users to read the whole range of books for free after purchase. From February 2019 to the present is the fourth phase of the adjustment stage. WeChat Reading is exploring the recommendation function of the "Take a look" information stream and the advertising cash model, as well as optimizing the details of each position.

\subsection{The Four Ps of Marketing theory analysis}

\subsubsection{Product strategy}

\subsubsection{Social sharing}

WeChat Reading app is reader-centric and linked by social relationships. The WeChat Reading app sets up a sharing and interaction mechanism of comparing and liking friends' reading hours to be updated weekly to stimulate reading. Users can see their WeChat friends' bookshelves, discover good quality books through their friends, and comment their friends' reading thoughts to strengthen social relationships.

\subsubsection{Personalised recommendations with "Guess Your Favorite"}

WeChat reading app uses artificial intelligence and big data technology to analyse users' reading situation and make intelligent recommendations, saving users' time to find books of interest.

\subsubsection{Pricing strategy}

\subsubsection{Free + paid pricing method}

Some books are free of charge, and a trial service is offered for popular books. This pricing method allows users to experience the books without considering buying them. It can lower users' psychological defences. According to statistics, the WeChat Reading app's free chapters account for about $40 \%$ of the entire book. Users need to read for more than 2 hours or read continuously for several days when their reading interest is most substantial, and their reading habit for this book has been formed. According to the China online reading industry marketing report released ${ }^{[5]}, 80 \%$ of users have a more stable tendency to pay, preferring to buy the whole book directly.There are two specific payment modes for users: to buy an unlimited card and become a member, and the other is to recharge reading coins and pay the book's price to complete the purchase.

\subsubsection{2. "Labour exchange" pricing method}

Users can purchase book resources through reading coins. There are two ways to obtain reading coins, one is by way of top-up, and the other is by exchange 
according to the length of reading. For example, users can exchange one reading coin for 30 minutes of reading. This process allows users to get into the habit of paying for books and ultimately selling them.

\subsubsection{Channel Strategy}

The main channels for WeChat reading app are app shop and social platform. Downloading in the app shops of Android and ios is an essential channel for WeChat Reading.From the data of Cicada Master's big data analysis platform, the download volume of WeChat Reading on the Android side has exceeded 900 million. The book app ranking of WeChat Reading on the ios side is No. 4 in 2020.Social platform for WeChat reading a vital channel, such as WeChat, microblogging, etc. The WeChat Reading app has modules such as "team up to draw unlimited cards", "give one get one free", and "buy one get one free". These modules drive users to share voluntarily to spread widely in the social chain, attracting more users, expanding the market share, and realising potential users' conversion to influential users.

\subsubsection{Promotion strategy}

Promotional strategies are mainly divided into "Selling Time" promotion strategy and "Give one, get one" promotion strategy. In an increasingly efficient society, competition pressure has increased, and people pay more attention to their development. "Selling Time" promotion strategy is redeeming users' reading time for reading vouchers is in line with people's increasing tendency to pay for knowledge to improve their quality. By redeeming reading vouchers for their efforts, users are more motivated and happy to read, and in this virtuous cycle, the WeChat Reading app's stickiness is strengthened. "Give one, get one" promotion strategy means that users can share the book with their friends and get the book's resources for themselves. Giving a book to a friend also creates a good image of yourself as a "book lover".The recipient must confirm the book's receipt before the giver can receive it, gaining a large number of new users through this sharing method.

\subsection{The problems of the WeChat reading app}

\subsubsection{The business model is relatively single}

WeChat Reading app attracts traffic by giving away unlimited cards, books and other freeways. Long-term use of this business model, so that users have inertia and dependence on the "free". The platform that wants to develop needs to spend costs. If the platform introduces more paid policies, users may resist and cause some users to lose.

\subsubsection{The proliferation of 'light reading'.}

The reading rankings section turns reading into a 'competition', which puts the reader in the spotlight and tends to shape the reader's relationship rather than the book itself. It also makes reading "shallow" , blurring reading attributes by socialisation. At the top of the WeChat Book rankings are novels, while there are fewer academic and in-depth articles. Over 80 per cent of WeChat Reader's users have a bachelor's degree or higher. The ranking is full of romance and fantasy, which is a proliferation of entertaining books and leads to the platform becoming "fast food". It is not conducive to its long-term development.

\subsection{Measures}

\subsubsection{Guide users to understand the "reading + social" reading style correctly}

The "reading + social" reading mode gives users a sense of achievement and satisfaction. The social function should serve reading, and the social process is only a "seasoning" for reading activities. Although the "reading + social" reading mode is a unique feature of WeChat Reading compared to other reading apps, excessive socialization may make the reading app seem sketchy and shallow, which is not conducive to long-term development. Therefore, the WeChat Reading app can balance reading and socialization.

\subsubsection{Subdividing audience groups and strengthening market positioning}

The WeChat reading app users are divided into three levels according to their stickiness, and different payment models are used for users at different levels.For users with low viscosity can give away books with lower selling prices to cultivate their reading habits and gradually transfer to users with low viscosity levels to those with high density.For high viscosity, users regularly do user feedback, listen to user suggestions and improve product quality. According to users' reading records and keyword search rate, push more accurately reading content and optimize the user experience.

\section{CONCLUSION}

At present, mobile reading has a broad development prospect, and social reading mode gradually becomes the mainstream trend of digital reading. WeChat Reading app occupies an essential position among mobile reading apps by its favourable price, abundant book resources, flexible reading time and "social experience + reading experience". However, the WeChat Reading app also has problems such as a shift in reading focus, a proliferation of superficial reading 
and a relatively single business model. Therefore, if WeChat Reading wants to achieve long-term development, it can allocate more reading resources, improve platform innovation, strengthen publicity and promotion, avoid excessive socialisation. To enhance its brand value and promote its development.

\section{ACKNOWLEDGMENTS}

First and foremost, I would like to show my deepest gratitude to my teachers and professors in my university, who have provided me with valuable guidance in every stage of the writing of this thesis. Further, I would like to thank all my friends for their encouragement and support. Without all their enlightening instruction and impressive kindness, I could not have completed my thesis.

\section{REFERENCES}

[1] Xiao Qian, Zhao Lu \& Zhang Cong. (2015). A new way of promoting books in reading apps from "ONE-One".Technology and Publishing (03), 58-61. doi:10.16510/j.cnki.kjycb.2015.03.025.

[2] Han X \& Zhang Q. (2019). Research on mobile reading behavior in the era of mobile internet taking WeChat reading app as an example. Publishing Wide Angle (24), 73-75. doi:10.16491/j.cnki.cn45-1216/g2.2019.24.021.

[3] Du. (2013). Mobile reading development trend and current countermeasures. China Publishing (22), 48-51. doi:CNKI:SUN:ZGCB.0.2013-22-013.

[4] Li Wu, Liu $\mathrm{Yu} \& \mathrm{Yu}$ Wen. (2013). A cross-national comparative study of mobile reading behavior among college students in China, Japan and Korea. Publishing Wide Angle (18), 8-11. doi:10.16491/j.cnki.cn45-1216/g2.2013.18.017.

[5] (2019). China online reading industry marketing report 2019. Shanghai Avery Marketing Consulting Co. (eds.) Ariadne Consulting Series Research Report (Issue 11, 2019) (pp. 361-404). 